\title{
Planta Medica Letters
}

Times are changing, and this certainly is true for scientific publishing! As Editor-in-Chief of Planta Medica - Official Organ of the Society for Medicinal Plant and Natural Product Research (GA) since 2007, I have witnessed the ever increasing importance of electronic media and electronic publications, as well as the rise of Open Access journals. "Open Access" refers to the fact that every person with an internet connection can access and read these articles. No fee is levied on the reader; the articles are free to read and download. Costs associated with scientific publishing (editorial processes, submission systems, production editing, typesetting, hosting on servers, longterm storage, marketing etc.) are covered by an "article-processing charge" (APC). An increasing number of (public) funding agencies request that results of their projects are made freely available to the public.

Due to the low threshold for electronic publications, and the fact that many electronic Open Access journals do not impose stringent quality criteria, we felt there was a need for an Open Access journal applying the same scientific standards as Planta Medica. Therefore, Thieme Publishers and the Society for Medicinal Plant and Natural Product Research (GA) agreed to start a sister journal, Planta Medica Letters, an international, English- language open access research journal accepting letters/short communications in the field of medicinal plant and natural product research. Basically the same "Guidelines for Authors" will apply but, apart from this, Planta Medica Letters will be established as an independent journal with its own Editorial Board, its own website and submission system. It should be emphasized that Planta Medica Letters should in no way be considered as a journal where preliminary research findings can be reported. Rather, Planta Medica Letters has a clear focus on concise, high-quality communications having a more limited scope than extensive studies, which still should find their way to Planta Medica.

The establishment of Planta Medica Letters is an important hallmark in the history of Planta Medi$c a$, and we look forward to receiving your submissions, which will contribute to the success of the journal!

Luc Pieters, Antwerp

Editor-in-Chief of Planta Medica Letters and Planta Medica

Matthias Hamburger, Basel

President of the Society for Medicinal Plant and Natural Product Research (GA)
Bibliography

DOI http://dx.doi.org/ 10.1055/s-0034-1368558

Planta Med Lett 2014; $1: 1$

(c) Georg Thieme Verlag KG

Stuttgart · New York .

ISSN 2199-157X

Correspondence

Prof. L. Pieters

Department of Pharmaceutical

Sciences

University of Antwerp

Universiteitsplein 1

2610 Antwerp

Belgium

luc.pieters@uantwerpen.be 